\title{
Significance of peritoneal cytology in patients with gastric cancer: a mono institutional experience with 50 patients
}

\author{
S. Maji, M.L. Saha, S.K. Sahu, P.B. Hagat \\ Department of Surgical Oncology, Chittaranjan National Cancer Institute, India
}

Keywords : Prognostic; gastric cancer; peritoneal; cytology

\section{Introduction}

The incidence of gastric cancer is different in different parts of the world. The incidence of gastric cancer is high in certain Southeast Asian countries namely Japan, China and South Korea [1]. However the incidence of gastric cancer in India is low as compared to global gastric cancer incidence [1].

Presentation is often delayed and leads to poor outcome with surgery alone. The most common site of locoregional failure is peritoneum. The Japanese Classification of Gastric Carcinoma (JCGC) has suggested the inclusion of peritoneal washing cytology as part of staging for gastric cancer and patients with positive (Intraperitoneal free cancer cells) IPFCC have been considered as Stage IV disease [2].

Positive peritoneal washing cytology has also been adopted by the American Joint Committee on Cancer (AJCC) staging system ( $7^{\text {th }}$ edition) in which positive cytology denotes M1 disease. Earlier studies have shown that patients with radiologically resectable disease but positive peritoneal cytology tend to have early disease recurrence and poor survival despite of $\mathrm{R} 0$ resection [4].

Patients with positive cytology often have dismal survival rates. Numerous studies have been done which confirms peritoneal cytology as an independent negative prognostic marker. Most of the data comes from the Western or Japanese literature. However no Indian study has been done on this respect. The present study aims to find out the role of peritoneal cytology in predicting prognosis in patients with gastric cancer.

\section{Material and methods}

The study was a prospective observational study and included 50 patients. The study duration was 1.5 years (from June 2012 to October 2014). The study included all operable

Correspondence: S. Maji

E-mail: drsuvendumaji@rediffmail.com DOI: http://10.4038/sljs.v34i4.8320 histologically proven gastric cancer cases. All patients who were found to have definitive organ metastasis on preoperative imaging were excluded from the study.

\section{Study technique}

All 50 patients underwent exploratory laparotomy via long midline incision. On opening the abdomen, $500 \mathrm{ml}$ sterile normal saline was instilled into the peritoneal cavity which was manually dispersed by shaking the abdomen. The primary tumour was not touched.

A washing sample $(100 \mathrm{ml})$ was aspirated from the peritoneal cavity. The specimen was immediately carried to the department of pathology, were sample was centrifuged to make smears which were fixed and stained with PAP (Papanicolau) stain and the slides examined under light microscope.

Peritoneal cytology was considered positive when malignant cancer cells were found in the smears. Medical records of each patient were then reviewed in detail and relevant clinical and pathological information were obtained. The patients were then followed for recurrence of disease and mortality either in our follow up clinic or by telephonic conversation. Associations between cytology status (CY) and clinicopathological variables and effect of cytology status on overall survival was evaluated.

\section{Study tools}

Pre structured questionnaire, preoperative staging investigations, pathology reports, cytology result.

\section{Data analysis}

Detailed history and examination and all relevant results were recorded using pre structured data sheet, the final pathology and cytology results were obtained and patient were followed up for an average of 15 months. All these data was entered into a Microsoft soft excel sheet and a master chart was prepared. This was used for making tables and diagrams to represent the data. Statistical correlation was done and tests of significance was calculated. Statistical analysis was done using statistical software R, version 2.13.0. 


\section{Results and analysis}

The average age of the patients was 51.76 years with age range being 25 to 75 years. $82 \%$ of the patients were males while $18 \%$ were females ratio. $56 \%$ of the patients had a rural background (Table 1). Based on occupation $24 \%$ were agricultural workers, $18 \%$ were daily wage workers (like manual labourers) while rest $58 \%$ could not be put into a specific group but were classified as "others" for convenience.

\begin{tabular}{|c|c|}
\hline Category & Percentage \% \\
\hline Age & \\
\hline $20-39$ & $6 \quad(12)$ \\
\hline $40-59$ & $33 \quad(66)$ \\
\hline $60-79$ & $11 \quad(22)$ \\
\hline \multicolumn{2}{|l|}{ Sex } \\
\hline Male & $41 \quad(82)$ \\
\hline Female & $9 \quad(18)$ \\
\hline \multicolumn{2}{|l|}{ Occupation } \\
\hline Agricultural workers & $12 \quad(24)$ \\
\hline Daily wage earners & $9 \quad(18)$ \\
\hline others & $29 \quad(58)$ \\
\hline \multicolumn{2}{|l|}{ Type of living } \\
\hline Rural & $28 \quad(56)$ \\
\hline Urban & $22 \quad(44)$ \\
\hline A & $7 \quad(25)$ \\
\hline B & $10(35.7)$ \\
\hline$A B$ & $4(14.28)$ \\
\hline $\mathrm{O}$ & $7 \quad(25)$ \\
\hline Unknown & 22 \\
\hline \multicolumn{2}{|l|}{ Smoking } \\
\hline Yes & $36 \quad(72)$ \\
\hline No & $14 \quad(28)$ \\
\hline
\end{tabular}

Table 1 Showing the demographic and clinicopathological data of the study population.
Table 2 shows weight loss was the most common symptom followed by dyspepsia and abdominal pain. According to Table 3 pyloric antrum was the commonest site of tumour and most common type of lesion was ulceroproliferative type $(50 \%) .18$ patients had poorly differentiated adenocarcinomas while only 3 had well differentiated carcinoma. Indeterminate type was the commonest histological subtype.

There were 20 patients in stage 1, 12 in stage 2, 13 in stage 3 and 5 had stage 4 disease.

The study sample was divided into two groups based on cytology results.

1. peritoneal cytology positive(CY1 tumours)

2. peritoneal cytology negative(CY0 tumours)

The association between demographic, clinicopathological variables and $\mathrm{CY}$ status was evaluated and presented in Table 4. For the age category, $\mathrm{p}$-value was calculated using independent sample t-test (2 tailed). All other p-values were calculated using chi-square test of significance. Out of 50 patients included in the study, 27 (54\%) had positive cytology while the rest 23 (46\%) had negative cytology.

\begin{tabular}{|l|c|}
\hline Symptoms & Percentage (\%) \\
\hline Weight loss & 72 \\
\hline Dyspepsia & 70 \\
\hline Generalized weakness/fatigue & 66 \\
\hline Pain abdomen & 60 \\
\hline Nausea/vomiting & 56 \\
\hline Postprandial abdominal fullness & 40 \\
\hline Malena & 24 \\
\hline Hematemesis & 12 \\
\hline Signs & 20 \\
\hline Lump Abdomen & \\
\hline Epigastric tenderness & \\
\hline
\end{tabular}

Table 2. Showing the symptoms and signs of the study sample 


\begin{tabular}{|c|c|}
\hline Parameters & Percentage \% \\
\hline \multicolumn{2}{|l|}{ Location of the tumour } \\
\hline Body & 16 \\
\hline Fundus & 12 \\
\hline Antrum & 72 \\
\hline \multicolumn{2}{|c|}{ Morphological type of tumour } \\
\hline Ulcerative & 26 \\
\hline Ulceroproliferative & 50 \\
\hline Others & 24 \\
\hline \multicolumn{2}{|c|}{ Histological grade of the tumour (adenocarcinomas) } \\
\hline Well differentiated & 6 \\
\hline Moderately Differentiated & 16 \\
\hline Poorly Differentiated & 36 \\
\hline NOS & 42 \\
\hline \multicolumn{2}{|c|}{ Type of lesions based on Laurens Classification } \\
\hline Intestinal & 16 \\
\hline Diffuse & 32 \\
\hline Indeterminate & 52 \\
\hline \multicolumn{2}{|c|}{ Stage of the tumour (AJCC) } \\
\hline Stage1 & 40 \\
\hline Stage2 & 24 \\
\hline Stage 3 & 26 \\
\hline Stage 4 & 10 \\
\hline \multicolumn{2}{|l|}{ Surgery } \\
\hline Resectable & 84 \\
\hline Unresectable & 16 \\
\hline
\end{tabular}

\begin{tabular}{|c|c|c|c|}
\hline Category & CYO $[n=23]$ & $\mathrm{CY} 1[\mathrm{n}=27]$ & $P$ value \\
\hline Age (years) & 52.04 & 51.52 & $0.866^{*}$ \\
\hline Sex & & & 0.525 \\
\hline Male & $18(43.90)$ & $23(56.10)$ & \\
\hline Female & $5(55.56)$ & $4(44.44)$ & \\
\hline Surgery & & & 0.038 \\
\hline Resection & $22(52.38)$ & $20(47.62)$ & \\
\hline No resection & $1(12.50)$ & $7(87.50)$ & \\
\hline Tumor category & & & 0.002 \\
\hline$T 1$ & $3(60)$ & $2(40)$ & \\
\hline$T 2$ & 16 (76.19) & $5(23.81)$ & \\
\hline T3 & 2 (14.29) & $12(85.71)$ & \\
\hline$T 4$ & $2(28.57)$ & $5(71.43)$ & \\
\hline$T x$ & $0(0)$ & $3(100)$ & \\
\hline Node category & & & 0.124 \\
\hline NO & $16(59.26)$ & $11(40.74)$ & \\
\hline N1 & $5(29.41)$ & $12(70.59)$ & \\
\hline Differentiation & & & 0.760 \\
\hline Well & $1(33.33)$ & $2(66.67)$ & \\
\hline Moderate & $5(62.50)$ & $3(37.50)$ & \\
\hline Poor & $8(44.44)$ & $10(55.56)$ & \\
\hline NOS & $9(42.86)$ & $12(57.14)$ & \\
\hline Morphological Types & & & 0.068 \\
\hline Ulcerative & $5(38.46)$ & $8(61.54)$ & \\
\hline Ulceroproliferative & $9(36)$ & $16(64)$ & \\
\hline Others & $9(75)$ & $3(25)$ & \\
\hline Lauren Classification & & & 0.455 \\
\hline Intestinal & $5(62.50)$ & $3(37.50)$ & \\
\hline Diffuse & $8(50)$ & $8(50)$ & \\
\hline Indeterminate & $10(38.46)$ & $16(61.54)$ & \\
\hline Chemotherapy & & & 0.908 \\
\hline Yes & $14(46.67)$ & $16(53.33)$ & \\
\hline No & $9(45)$ & $11(55)$ & \\
\hline
\end{tabular}

The Sri Lanka Journal of Surgery 2016; 34(4): 34-39 
There were 42 patients in the resectable category while 8 patients were unresectable. Among the individuals in whom the tumour was surgically resectable, cytology was negative in $52.38 \%$ cases. Whereas $87.50 \%$ of the surgically unresectable cases had peritoneal cytology positive.

In other words among the individuals with negative peritoneal cytology, tumour was significantly (0.038) more likely to be resectable. In case of tumour category significant association exists between peritoneal cytology and tumour category (0.002). However no statistically significant association was found between peritoneal cytology finding and node category $(\mathrm{p}=0.124)$, differentiation of the tumour $(\mathrm{p}=0.760)$, morphological type $(\mathrm{p}=0.068)$ or Lauren classification $(\mathrm{p}=0.455)$

Overall survival for the groups are depicted in Fig 1 (Kaplan Meir survival curve). Individuals with negative cytology did not fall below the 0.5 probability of dying (or recurrence) within the observation period so median survival could not be calculated for those with negative cytology.

For individuals with positive cytology, median survival is 10 months. Implying that, there is $50 \%$ probability for individuals with positive peritoneal cytology at the time of the diagnosis to die or develop recurrence within 10 months. Log-rank test showed that this difference in the probability of the survival is statistically significant ( $\mathrm{p}=0.000695$ or $\mathrm{p}<$ 0.05). Cox proportional hazard model was used to identify prognostic factors in the sample, the results of which are shown in Table 5. Bold values in the table are the one showing the significant findings.

Values in the parenthesis indicate the $95 \%$ confidence interval for the calculated hazard ratio. If a patient died or the tumour recurred, it was considered as a bad outcome. Probability of having a bad outcome was not statistically significantly associated with age and sex in the univariable analysis. It was significantly associated with clinical tumour category, clinical node category and peritoneal cytology findings. Compared to N0, Nx had almost 10 fold higher probability of having the bad outcome. Compared to T1, T4 and Tx had almost 12 and 150 fold higher probability of having the bad outcome.

However the number of patients in both of this group were very small. Compared to negative peritoneal cytology, individuals with positive peritoneal cytology had 5 times higher risk of having the bad outcome.

Ideally, the independent variables of a multivariable model should not have any association among themselves. As peritoneal cytology had association with clinical tumour category, peritoneal cytology was not included in the final multivariable model. In the multivariable model, only clinical tumour category remained significantly associated with bad outcome. Clinical node category lost its significance after adjusting for other factors. After adjusting for other factors, $\mathrm{T} 4$ and Tx, only, remained significant. Individuals with T4 and Tx tumour stage had almost 21 and 235 times higher probability of having the bad outcome. The high value of the confidence intervals are because of the small sample size.

\section{Discussion}

The epidemiological profile of our study sample in terms of age, sex, residence, presenting symptoms, tumour type, tumour site, histology were almost comparable to the findings of previous Indian investigators [1,12].

Although the use of newer imaging modalities has greatly improved the locoregional staging of gastric cancer, the rate of preoperative detection of peritoneal dissemination continues to be dismal. According to previous studies presently available radiological imaging has poor sensitivity in picking peritoneal metastases [1].

The best method for diagnosis of peritoneal dissemination is still thorough exploratory laparotomy or laparoscopy. Brito et al [5] included 72 patients of gastric adenocarcinomas, with peritoneal lavage cytology positive in $11.1 \%$ cases. Whereas Mezhir [6] et al studied 1241 patients and showed 23\% positive cytology. Lee et al [7] in his study of 1072 patients showed $16 \%$ positive cytology. Bhatti etal [8] from Pakistan showed in their retrospective studies of 149 patients, $40 \%$ rate of positive peritoneal cytology obtained using laparoscopy. Unlike all this studies the rate positive peritoneal cytology was very high in our study (54\%). We could not find any Indian study to correlate our results. Most of the above investigators used $200 \mathrm{ml}$ of normal saline for peritoneal washing.

However we used $500 \mathrm{ml}$ of normal saline in each case for convenience as retrieval of adequate $(100 \mathrm{ml})$ of specimens with only $200 \mathrm{ml}$ was practically difficult. Median overall survival was 20 months for cytology positive patients in Lee et al group.

According to Chuwa [8] et al patients with positive cytology showed a mean survival of 27 months while in the Mezhir group it was 1.3 years for the cytology positive group. In our study series median survival was only 10 months for the cytology positive group which is quite low as compared to previous studies.

Many studies have found a link between progression of tumour through the muscle layer, lymph node metastasis and angiolymphatic invasion with the presence of malignant cells in the peritoneal cavity $[9,10,11]$. However unlike the above studies our analysis showed that positive cytology was significantly associated with the $\mathrm{T}$ (depth of tumour invasion) stage and resectability status of the tumors. This may be 


\begin{tabular}{|c|c|c|c|c|}
\hline \multirow[t]{2}{*}{ Category } & \multirow{2}{*}{$\begin{array}{l}\text { Univariable analysis } \\
\text { Hazard ratio }\end{array}$} & \multicolumn{3}{|c|}{ Multivariable analysis } \\
\hline & & P-value & Hazard ratio & P -Value \\
\hline \multicolumn{5}{|l|}{ Age } \\
\hline$<60$ years & 1.00 (Reference) & & 1.00 (Reference) & \\
\hline$\geq 60$ years & $0.73(0.27,2.00)$ & 0.54 & $0.96(0.31,2.92)$ & 0.94 \\
\hline \multicolumn{5}{|l|}{ Sex } \\
\hline Female & 1.00 (Reference) & & 1.00 (Reference) & \\
\hline Male & $1.66(0.49,5.63)$ & 0.42 & $2.27(0.38,2.23)$ & 0.36 \\
\hline \multicolumn{5}{|c|}{ Clinical Tumor Category } \\
\hline T1 & 1.00 (Reference) & & 1.00 (Reference) & \\
\hline $\mathbf{T} 2$ & $1.11(0.13,3.53)$ & 0.92 & $1.21(0.14,2.93)$ & 0.86 \\
\hline T3 & $2.33(0.28,3.32)$ & 0.43 & $1.91(0.22,2.77)$ & 0.55 \\
\hline T4 & $2.27(1.46,3.54)$ & 0.02 & $1.29(1.06,2.16)$ & 0.01 \\
\hline $\mathbf{T x}$ & $2.69(1.18,3.14)$ & 0.001 & $3.14(1.33,5.22)$ & 0.001 \\
\hline \multicolumn{5}{|c|}{ Clinical node category } \\
\hline No & 1.00 (Reference) & & 1.00 (Reference) & \\
\hline N1 & $1.60(0.60,4.26)$ & 0.35 & $2.21(0.72,6.81)$ & 0.17 \\
\hline $\mathbf{N x}$ & $1.87(1.09,2.18)$ & 0.001 & $1.04(0.09,2.21)$ & 0.97 \\
\hline \multicolumn{5}{|c|}{ Peritoneal Cytology } \\
\hline Negative & 1.00 (Reference) & & & \\
\hline Positive & $1.44(1.03,2.11)$ & 0.001 & & \\
\hline
\end{tabular}

Table 5 Cox proportional hazard analysis of prognostic factors 


\section{References}

1. Sharma A, Radhakrishnan V.Gastric cancer in India. Indian Journal of Medical and Paediatric Oncology : Official Journal of Indian Society of Medical \& Paediatric Oncology 2011; 32(1):12-16. doi:10.4103/0971-5851.81884 https://doi.org/10.4103/0971-5851.81884

2. Japanese Gastric Cancer Association (1998) Japanese Classification of Gastric Carcinoma - 2nd English Edition Gastric Cancer 1: 10-24. https://doi.org/10.1007/PL00011681

3. Edge SB, Byrd DR, Compton CC. AJCC cancer staging manual, 7th ed. New York: Springer; 2010

4. Ang CW, Tan LC (2013) Peritoneal Cytology in the Staging Process of Gastric Cancer: Do or Don't? J Gastroint Dig Syst 3:156. doi: 10.4172/2161-069X.1000156 https://doi.org/10.4172/2161-069X.1000156

5. BRITO, Alexandre Menezes et al . Prognostic role of positive peritoneal cytology in patients with resectable gastric cancer. Rev. Col. Bras. Cir. Rio de Janeiro, v. 40, n. 2, Apr. 2013

6. Mezhir JJ, Shah MA, Jacks LM, Brennan MF, Coit DG, Strong VE. Positive peritoneal cytology in patients with gastric cancer: natural history and outcome of 291 patients. Ann Surg Oncol. 2010; 17:3173-3180 https://doi.org/10.1245/s10434-010-1183-0

7. Lee SD, Ryu KW, Eom BW, Lee JH, Kook MC, Kim YW.
Prognostic significance of peritoneal cytology in patients with gastric cancer. Br J Surg. 2012; 99:397-403

https://doi.org/10.1002/bjs.7812

8. Chuwa EW, Khin LW, Chan WH, Ong HS, Wong WK. Prognostic significance of peritoneal lavage cytology in gastric cancer in Singapore. Gastric Cancer. 2005; 8(4):22837. https://doi.org/10.1007/s10120-005-0343-6

9. Rosenberg R, Nekarda H, Bauer P, Schenck U, Hoefler H, Siewert JR. Free peritoneal tumour cells are an independent prognostic factor in curatively resected stage IB gastric carcinoma. Br J Surg. 2006; 93(3):325-31. https://doi.org/10.1002/bjs.5196

10. Euanorasetr C, Lertsithichai P. Prognostic significance of peritoneal washing cytology in Thai patients with gastric adenocarcinoma undergoing curative D2 gastrectomy. Gastric Cancer. 2007; 10(1):18-23 https://doi.org/10.1007/s10120-006-0402-7

11. Kaplan E, Meier P. Nonparametric estimation from incomplete observations. J Am Stat Assoc. 1958; 53(282):457-81. https://doi.org/10.1080/01621459.1958.10501452

12. Saha kr Ashish. Epidemiology of Gastric Cancer in the Gangetic Areas of West Bengal. ISRN GASTROENTEROLOGY.2013

13. Cox DR. Regression models and life tables. J R Stat Soc 1972; 34:248-75 